\title{
Extract of Pogostemon cablin Possesses Potent Anticancer Activity against Colorectal Cancer Cells In Vitro and In Vivo
}

\author{
Ju-Huei Chien, ${ }^{1,2}$ Shan-Chih Lee, ${ }^{3,4}$ Kai-Fu Chang, ${ }^{5,6}$ Xiao-Fan Huang, ${ }^{5,6}$ \\ Yi-Ting Chen, ${ }^{6}$ and Nu-Man Tsai ${ }^{6,7}$ \\ ${ }^{1}$ Department of Laboratory Medicine, Taichung Tzu-Chi Hospital, Buddhist Tzu-Chi Medical Foundation, \\ Taichung 42743, Taiwan \\ ${ }^{2}$ Department of Medical Laboratory Science and Biotechnology, Central Taiwan University of Science and Technology, \\ Taichung 40601, Taiwan \\ ${ }^{3}$ Department of Medical Imaging and Radiological Sciences, Chung Shan Medical University, Taichung 40201, Taiwan \\ ${ }^{4}$ Department of Medical Imaging, Chung Shan Medical University Hospital, Taichung 40201, Taiwan \\ ${ }^{5}$ Institute of Medicine, Chung Shan Medical University, Taichung 40201, Taiwan \\ ${ }^{6}$ Department of Medical Laboratory and Biotechnology, Chung Shan Medical University, Taichung 40201, Taiwan \\ ${ }^{7}$ Clinical Laboratory, Chung Shan Medical University Hospital, Taichung 40201, Taiwan \\ Correspondence should be addressed to Nu-Man Tsai; numan@csmu.edu.tw
}

Received 11 June 2020; Revised 10 August 2020; Accepted 25 August 2020; Published 9 September 2020

Academic Editor: Luísa Zuravski

Copyright ( $92020 \mathrm{Ju}-\mathrm{Huei}$ Chien et al. This is an open access article distributed under the Creative Commons Attribution License, which permits unrestricted use, distribution, and reproduction in any medium, provided the original work is properly cited.

\begin{abstract}
Pogostemon cablin (PCa), an herb used in traditional Chinese medicine, is routinely used in the amelioration of different types of gastrointestinal discomfort. However, the mechanisms underlying the cancer suppression activity of PCa in colorectal cancer (CRC) cells have yet to be clarified. The aim of this study was to investigate the anticancer effects of PCa, specifically the induction of apoptosis in CRC cells. The growth inhibition curve of CRC cells following exposure to PCa was detected by an MTT assay. Moreover, PCa combined with 5-FU revealed a synergic effect of decreased cell viability. PCa inhibited cell proliferation and induced cell cycle arrest at the $G_{0} / G_{1}$ phase and cell apoptosis through regulation of associated protein expression. An in vivo study showed that PCa suppressed the growth of CRC via induction of cell apoptosis with no significant change in body weight or organ histology. Our results demonstrated that PCa inhibits the growth of CRC cells and induces apoptosis in vitro and in vivo, which suggests the potential applicability of PCa as an anticancer agent.
\end{abstract}

\section{Introduction}

Colorectal cancer (CRC) is one of the most common malignant cancer types. It has a high incidence in developed countries [1]. In 2018, around 1.85 million cases were diagnosed, and 880,792 deaths occurred from CRC worldwide [2]. The 5-year survival rate is around $90 \%$ for patients diagnosed with early-stage cancer; however, the 5-year survival rate drops to only $10 \%$ if there is distant metastasis at the time of diagnosis. The first line of treatment is surgery with curative potential for CRC patients [3], which is performed in $75-80 \%$ of newly diagnosed patients with localized or regional tumors; however, around $50 \%$ of them will develop a recurrence after surgery $[4,5]$. Chemotherapy is used as adjuvant therapy for prevention of local recurrences or distant metastases. 5-Fluorouracil (5-FU), the first-line chemotherapeutic drug of CRC, is an antimetabolite agent that has poor efficacy against CRC, with only $10 \%$ to $15 \%$ of patients responding $[6,7]$, due to the limitations of severe side effects and the development of drug resistance $[8,9]$. Therefore, it is necessary to develop novel therapeutic agents or strategies for CRC therapy.

Natural products have been recognized as a source of bioactive components, and they are used in both traditional health care systems and new drugs development [10]. More novel natural products with high bioefficiency and low 
toxicity have been discovered, and they have the potential for development into new drugs that are not derived from fully synthetic or combined synthetic compounds [11, 12]. Many reports have revealed that approximately half of all approved drugs were developed from natural plants, such as paclitaxel, vinblastine, and etoposide [13-15]. In cancer therapy, natural products or their derivatives not only induce cell apoptosis but also act against the resistance of cancer cells to chemotherapeutic drugs through regulation of cell apoptosis or combination treatment [16-18]. Therefore, natural products have been introduced as a potential strategy for cancer treatment and prevention.

Pogostemon cablin (PCa) is an herb that has been used in traditional Chinese medicine for hundreds of years to clinically ameliorate gastrointestinal diseases and dispel dampness and superficies syndrome [19], and it has been used as a complementary anticancer agent for a few years [20]. The major compounds in PCa include patchouli alcohol, azulene, $\alpha$-guaiene, and seychellene $[19,21]$. The biological activities of PCa have been widely reported, including anti-inflammatory, antioxidative, antimicrobial, analgesic, antiplatelet, antithrombotic, antidepressant, and antiemetic effects $[19,22,23]$. In a previous study, Pogostemon cablin aqueous extract could induce apoptosis in endometrial cancer cells in vitro [24]. However, the anticancer activity of $\mathrm{PCa}$ is yet to be clarified in CRC in vitro and in vivo. Here, we investigated the activities and mechanisms of $\mathrm{PCa}$ against CRC cells both in vitro and in vivo.

\section{Materials and Methods}

2.1. Chemicals and Reagents. MTT (3-(4,5-dimethylthiazol2-yl)-2,5-diphenyltetrazolium bromide), dimethyl sulfoxide (DMSO), 5-fluorouracil (5-FU), propidium iodide (PI), and RNase were obtained from Sigma-Aldrich (St. Louis, CA, USA). Dulbecco's modified Eagle medium (DMEM) and Roswell Park Memorial Institute Medium-1640 (RPMI), fetal bovine serum (FBS), HEPES, pyruvate, and penicillin-streptomycin (S/P) were from Gibco-BRL (Grand Island, NY, USA). The leaves of Pogostemon cablin were from Republik Indonesia, with confirmation of identification by Professor Han-Ching Lin. The small-scale extraction was prepared in our laboratory, and the conditions were described as follows. The leaves of Pogostemon cablin (500 g) were dehydrated, crushed, and placed in a $2 \mathrm{~L}$ steam distillation steel apparatus unit. Extraction was performed by hydrodistillation with a flow rate of approximately $7.2 \mathrm{ml} / \mathrm{min}$ at $100^{\circ} \mathrm{C}$ for $100 \mathrm{~min}$, and the yields were about $2.09 \%$. The large scale of PCa extract was entrusted by Phoenix (New Jersey, USA).

2.2. Cell Culture and Treatment. Human colorectal adenocarcinoma cells (HT-29), mouse colon carcinoma cells (CT26), mouse vascular endothelial cells (SVEC), and canine kidney epithelial cells (MDCK) were purchased from the Food Industry Research and Development Institute (Hsinchu, ROC). Cells were cultured in DMEM (HT-29, SVEC, and MDCK cells) and RPMI (CT26 cells) supplemented with 10\% FBS, HEPES, pyruvate, and S/P and maintained at $37^{\circ} \mathrm{C}$ in a humidified incubator with $5 \% \mathrm{CO}_{2}$. The status of TP53, BRAF, KRAS, and PIK3CA in the HT-29 cells were mutated, detected using automated extraction of nucleic acids (AccuBioMed Co., Ltd., Taipei, Taiwan) and FemtoPath Human Primer Sets (HongJing Biotech, Taipei, Taiwan). The stock solution $(50 \mathrm{mg} / \mathrm{ml})$ of PCa was prepared in dimethylsulfoxide (DMSO) immediately before use, and the cells were treated with PCa at different times $(30 \mu \mathrm{g} / \mathrm{ml}$ for $0-48 \mathrm{~h})$ and at different dosages $(0-45 \mu \mathrm{g} / \mathrm{ml}$ for $24 \mathrm{~h})$.

2.3. Cytotoxicity Assay. The cell viability was detected by an MTT assay. Cells at a density of $5 \times 10^{3}$ cells/well were cultured in 96-well culture plates overnight and then treated with different concentrations of PCa or 5-FU for 24, 48, and $72 \mathrm{~h}$. Then, the culture medium was replaced with MTT solution ( $400 \mu \mathrm{g} / \mathrm{ml}$, Sigma) and incubated for 6-8 h. Later, the formazan crystals were dissolved in $50 \mu \mathrm{l}$ DMSO, and the absorbance intensity was measured with a microplate reader (Molecular Device/Spec384) at $550 \mathrm{~nm}$. Percentage of cell survival was calculated using the following formula: cell viability $(\%)=$ intensity (treated cell)/intensity (control cell) $\times 100 \%$.

2.4. Determination of Combination Effect. HT-29 cells were seeded in 96-well culture plates and treated with PCa $(0,10$, 20,40 , or $80 \mu \mathrm{g} / \mathrm{ml}$ ) combined with $1.5 \mu \mathrm{g} / \mathrm{ml} 5$-FU or $5-\mathrm{FU}$ $(0,1,2,4$, or $8 \mu \mathrm{g} / \mathrm{ml})$ combined with $30 \mu \mathrm{g} / \mathrm{ml}$ PCa for $48 \mathrm{~h}$, and then we detected the cell viability by an MTT assay. The value of the combination index (CI), determined synergism $(\mathrm{CI}<1)$, additive effect $(\mathrm{CI}=1)$, and antagonism $(\mathrm{CI}>1)$ were calculated by the following: $\left[\mathrm{IC}_{50}\right.$ (drug $\left.\mathrm{A}+\mathrm{B}\right) / \mathrm{IC}_{50}$ $(\operatorname{drug} \mathrm{A})]+\left[\mathrm{IC}_{50}(\operatorname{drug} \mathrm{A}+\mathrm{B}) / \mathrm{IC}_{50}(\operatorname{drug} \mathrm{B})\right][25]$.

2.5. Detection of the Cell Cycle Stage. Cell cycle progression was analyzed by flow cytometry through the determination of DNA content in cell nuclei stained with propidium iodide (PI). The treated cells were harvested and stained by incubation in PBS containing $40 \mu \mathrm{g} / \mathrm{ml} \mathrm{PI}$ and $100 \mu \mathrm{g} / \mathrm{ml}$ RNase for 30 minutes at $4^{\circ} \mathrm{C}$. The fractions of the cells in the $\mathrm{G} 1, \mathrm{~S}$, and G2 phases were measured and analyzed using a FACScan (Beckton Dickinson, USA) and FlowJo software (Tree Star, San Carlos, CA, USA).

2.6. TUNEL Assay. Apoptosis was determined by using an In Situ Cell Death Detection Kit (TUNEL), POD (Roche, Mannheim, Germany) according to the manufacturer's instructions. Cells smeared on silane-coated slides or deparaffinized tissue sections were incubated with $3 \% \mathrm{H}_{2} \mathrm{O}_{2}$ in methanol and $0.1 \%$ Triton $\mathrm{X}-100$ in $0.1 \%$ sodium citrate buffer on ice to increase the cells' permeability. Cells or tissues were incubated with a TUNEL detection kit for $2 \mathrm{~h}$ at $37^{\circ} \mathrm{C}$, counterstained with PI staining, and observed under a fluorescence microscope (ZEISS AXioskop 2) at 400× magnification. 
2.7. Western Blot Analysis. The procedures of protein extraction and Western blotting were performed as previously described [26]. Specific primary antibodies used in this study included those against p53, p-p53, p21, p-Rb, PCNA, CDK2, CDK4, cyclin A, cyclin B1, cyclin D1, FAS, Caspase-8, Bax, Caspase-9, Caspase-3, MMP2, and MMP9 (Santa Cruz, CA, USA); $\beta$-actin (iReal Biotechnology Co., Ltd., Hsinchu, Taiwan). The antigen-antibody complexes were detected by a chemiluminescence imaging analyzer (GE LAS-4000, GE Healthcare Life Sciences, NJ, USA), and the signal intensity of each band was determined by using ImageJ software $1.47 \mathrm{t}$ (National Institutes of Health, Bethesda, MD, USA).

2.8. Animal Study. BALB/c female mice (10-12 weeks, 19-23 g) were purchased from the National Laboratory Animal Center (Taipei, ROC) and housed, 6 per cage, in a laminar airflow room and maintained on laboratory standard experimental conditions (relative humidity 55-60\%, dark/light cycle $12 / 12 \mathrm{~h}$, and free access to balanced diet and water at a temperature of $25 \pm 1^{\circ} \mathrm{C}$ ). Mice were adapted to laboratory conditions for a week before experimentation. The research was performed in Chung Shan Medical University (CSMU) following the Guide for the Care and Use of Laboratory Animals and approved by the Institutional Animal Care and Use Committee (IACUC) of CSMU (Approval no. CSMU-IACUC-1543). The mice $(n=10)$ were subcutaneously injected with $1 \times 10^{6}$ CT26 cells in PBS into the flank. Seven days later, the tumor-bearing mice were randomly divided into 2 groups: $(1)$ vehicle $(n=4)$ were treated with $5 \%$ DMSO in PBS by subcutaneous injection and (2) PCa groups $(n=6)$ were treated with $200 \mathrm{mg} / \mathrm{kg} \mathrm{PCa}$ by subcutaneous injection once every 2 days for 40 days. Tumor size and body weight were recorded every 2 days. When the tumor volume was greater than $1500 \mathrm{~mm}^{3}\left(L \times H \times W \times \pi / 6 \mathrm{~mm}^{3}\right)$, mice were sacrificed using carbon dioxide. The organs, including the liver, kidney, and intestine, were collected, fixed with $4 \%$ neutral formalin, embedded in paraffin, and cut for $\mathrm{HE}$ staining analysis. Sections were deparaffinized, rehydrated, stained with hematoxylin and eosin (Muto Pure Chemicals, Tokyo, Japan), observed, and photographed under a bright-field microscope.

2.9. Statistical Analysis. Data were analyzed using Student's $t$-test, and the survival rate was analyzed using the Kaplan-Meier method to determine the statistical significance of differences $(P$ values of <0.05). The results are expressed as the mean \pm standard deviation (SD) for the in vitro data or standard error (SE) for the in vivo data.

\section{Results}

3.1. PCa Inhibited the Growth of CRC Cells In Vitro. The PCa was diluted in hexane $(1: 50)$, analyzed with a GC-MS, and identified via comparison with mass spectra from the literature and the NIST and Wiley Library databases. The major components smaller than 500 daltons in the PCa included azulene (21.81\%), $\alpha$-guaiene (18.85\%), patchouli alcohol (18.16\%), $\alpha$-patchoulene (11.14\%), $\quad \gamma$-gurjunene (9.31\%), and others (data not shown). MTT assays were conducted to examine the cytotoxicity of PCa against HT-29 and CT26 cells. There was a dose-dependent cytotoxic effect of PCa treatment for 24-48 h against CRC cells (Figures 1(a) and 1(b)). However, the cytotoxicity against the normal cells (SVEC and MDCK) was lower than that for the CRC cells (Figures $1(\mathrm{c})$ and $1(\mathrm{~d})$ ). The $\mathrm{IC}_{50}$ values of HT-29, CT26, SVEC, and MDCK were $21.04 \pm 0.68,15.46 \pm 1.28$, $40.35 \pm 2.91$, and $68.55 \pm 0.28 \mu \mathrm{g} / \mathrm{ml}$ for $48 \mathrm{~h}$, respectively (Table 1). These results suggest that PCa inhibited the growth of CRC cells in a dose-dependent manner but was less cytotoxic to normal cells.

3.2. PCa Combined with 5-FU Synergistically Inhibited CRC Cells. To determine the effect of a combination of PCa and 5-FU, HT-29 cells were treated with PCa $(10,20,40$, or $80 \mu \mathrm{g} /$ $\mathrm{ml})$ combined with 5 -FU $1.5 \mu \mathrm{g} / \mathrm{ml}$ or $5-\mathrm{FU}(1,2,4$, or $8 \mu \mathrm{g}$ / ml) combined with PCa $30 \mu \mathrm{g} / \mathrm{ml}$. The cell viability was measured by using an MTT assay after treatment for $48 \mathrm{~h}$. As shown in Figure 2, the viability of the drugs combination group was not only lower than that of the PCa only but also than that of the 5-FU only, and the combination index (CI) was 0.65 , indicating a synergistic effect $(\mathrm{CI}<1)$. These results pointed to a synergistic effect of the activity of PCa and 5-FU against CRC cells.

3.3. Effect of PCa on Cell Cycle Arrest in HT-29 Cells. The PCa-induced decrease in cell viability could have been a result of decreased proliferation. Next, to investigate whether PCa induced cell cycle arrest, flow cytometry was used to analyze the distribution of the cells in the cell cycle. After the HT-29 cells were treated with PCa for different times or at different doses, the percentage of cells in the $G_{0} /$ $\mathrm{G}_{1}$ phase was increased in doses of 15 and $30 \mu \mathrm{g} / \mathrm{ml}$ (Figures 3(a) and 3(b)), indicating PCa-induced cell cycle arrest in the $G_{0} / G_{1}$ phase. The protein expression of $p 53$, p-p53, and p21 was increased, but that of p-Rb, PCNA, CDK2, CDK4, cyclin A, cyclin B1, and cyclin D1 was decreased in the PCa-treated cells (Figure 3(c)). Therefore, these results suggested that $\mathrm{PCa}$-induced growth inhibition of CRC cells was associated with cell cycle arrest via the regulation of cell cycle regulators.

3.4. PCa Promotes Cell Apoptosis in CRC Cells. The percentage of cells in the $S_{u b G_{1}}$ phase was significantly increased in PCa-treated cells compared with the control as determined by flow cytometry (Figures 4(a) and 4(b)). Next, to determine the effect of PCa on apoptosis, PCa-treated cells were subjected to a TUNEL assay. The PCa-treated cells had positive TUNEL results and exhibited morphology consistent with cell apoptosis, such as chromatin condensation, DNA fragmentation, and apoptosis bodies (Figure 4(c)). In the apoptotic molecular analysis, PCa promoted the expression and activation of Fas/caspase-8, Bax/caspase-9, and caspase-3 (Figure $4(\mathrm{~d})$ ). All of these results suggested that 


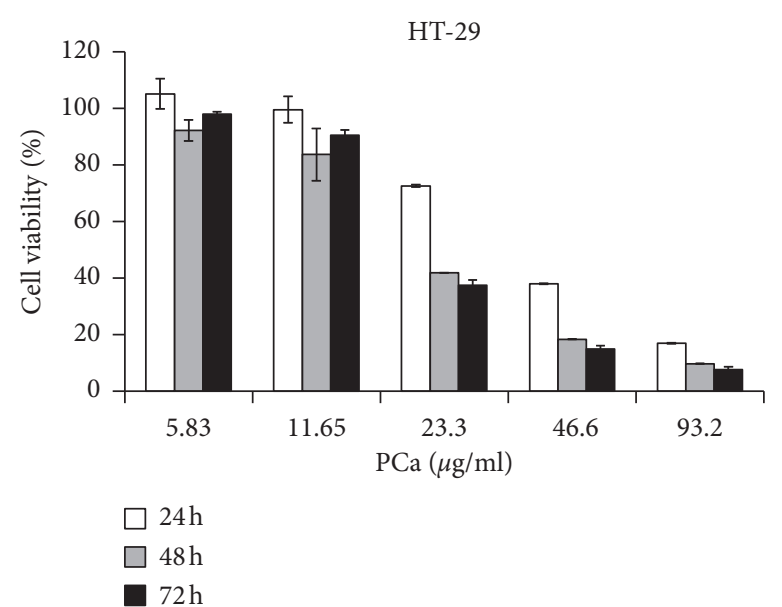

(a)
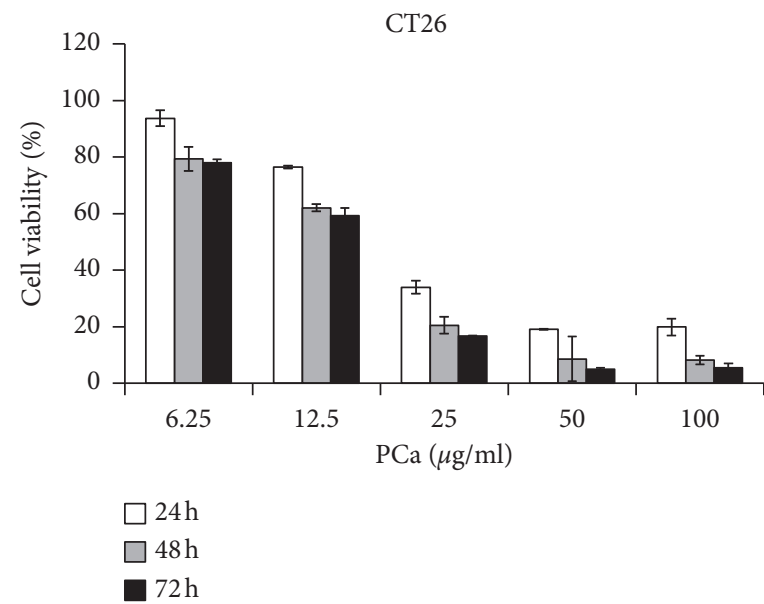
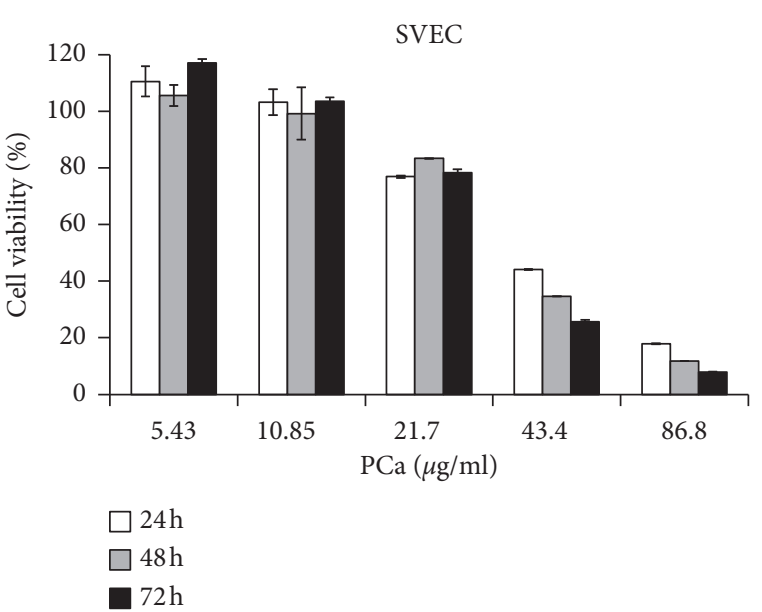

$72 \mathrm{~h}$

(b)

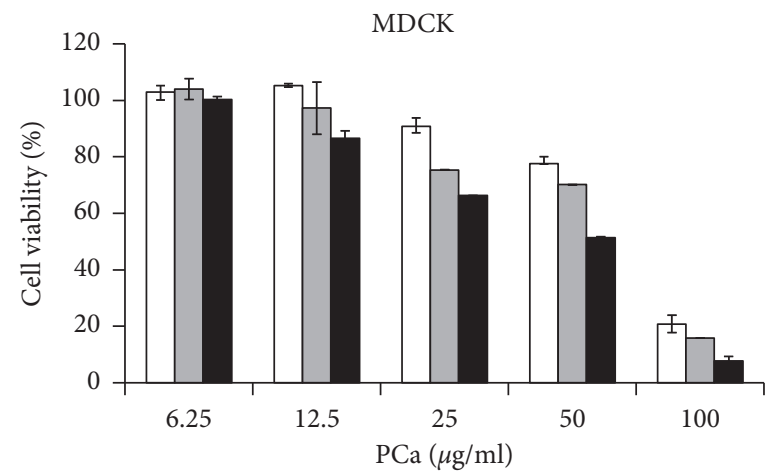

$\square 24 \mathrm{~h}$
$\square 48 \mathrm{~h}$
$\square 72 \mathrm{~h}$

(c)

(d)

FIGURE 1: Effect of PCa on cell survival and proliferation of CRC cells. Cell viability was determined by using an MTT assay after treatment for 24, 48, or $72 \mathrm{~h}$ with increasing concentrations of PCa. (a) HT-29, (b) CT26, (c) SVEC, and (d) MDCK cells. The percentage of cell viability was normalized to the control (100\%). The results are expressed as mean \pm SD.

TABLE 1: The $\mathrm{IC}_{50}$ values of PCa against CRC and normal cells.

\begin{tabular}{lccc}
\hline Cell line & Tumor type & PCa & $5-\mathrm{FU}$ \\
\hline HT-29 & Human colorectal adenocarcinoma & $21.04 \pm 0.68^{\mathrm{a}, \mathrm{b}}$ & $8.60 \pm 1.52$ \\
CT26 & Mouse colon carcinoma & $15.46 \pm 1.28^{\mathrm{a}, \mathrm{b}}$ & $0.3 \pm 0.01$ \\
SVEC & Mouse endothelia cell & $40.35 \pm 2.91^{\mathrm{a}}$ & $<6.25$ \\
MDCK & Canine kidney epithelial cell & $68.55 \pm 0.28^{\mathrm{a}}$ & $12.30 \pm 1.53$ \\
\hline
\end{tabular}

Note. Values are expressed as mean $\pm \mathrm{SD}(\mu \mathrm{g} / \mathrm{ml})$ at $48 \mathrm{~h} .{ }^{\mathrm{a}} \mathrm{A}$ significant difference between the PCa group compared with the 5-FU group. ${ }^{\mathrm{b}} \mathrm{A}$ significant difference between the CRC cells compared with normal cells.

PCa induced cell apoptosis through the activation of caspases in CRC cells.

\subsection{PCa Reduced Protein Expression of Factors Involved in} Metastasis. Previous studies indicated the fact that high metastasis resulted in a poor prognosis of CRC patients. Therefore, we investigated whether PCa regulated metastasis-associated protein expression. Western blotting showed that PCa reduced the expression of the metastasis proteins MMP2 and MMP9 (Figure 5). These results indicated that PCa has a potential effect on antimetastasis of CRC cells.

3.6. PCa Suppressed the Growth of CRC in Tumor-Bearing Mice. To examine the antitumor effects of $\mathrm{PCa}$ in vivo, a therapeutic animal model was established by transplanting CT26 cells into BALB/c female mice. As shown in Figures 6(a) and 6(b), the tumor volume in the PCa group $\left(1121.07 \pm 187.65 \mathrm{~mm}^{3}\right)$ was smaller than that in the vehicle group $\left(1577.33 \pm 146.49 \mathrm{~mm}^{3}\right)$ at day 25 , and there was a 


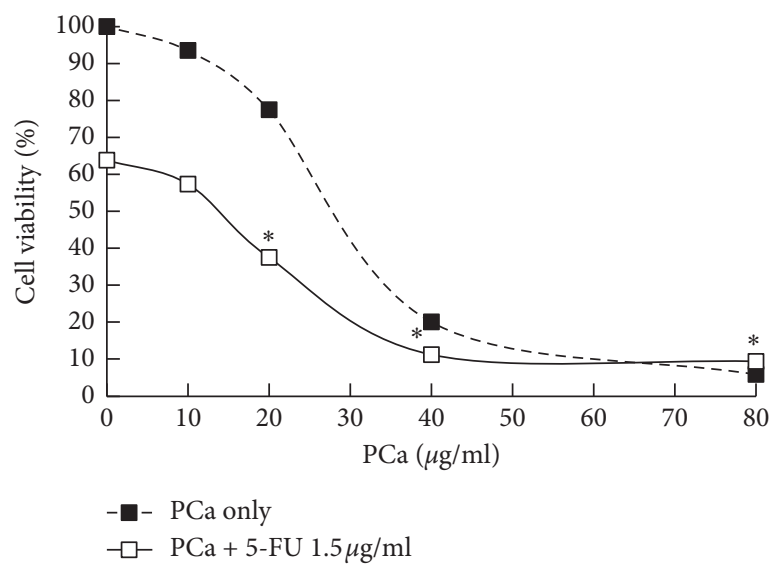

(a)

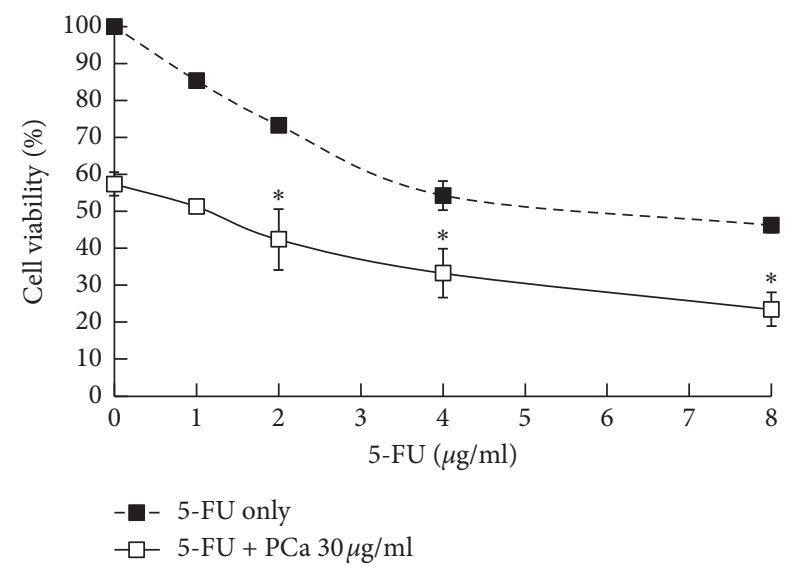

(b)

Figure 2: PCa and 5-FU synergistically inhibited the growth of HT-29 cells in vitro. HT-29 cells were treated with (a) PCa (0, 10, 20, 40, or $80 \mu \mathrm{g} / \mathrm{ml})$ and/or 5 -FU $(1.5 \mu \mathrm{g} / \mathrm{ml})$, (b) 5 -FU $(0,12,4$, or $8 \mu \mathrm{g} / \mathrm{ml})$ and $/$ or PCa $(30 \mu \mathrm{g} / \mathrm{ml})$ for $48 \mathrm{~h}$, and then we measured cell viability by using an MTT assay. PCa and 5-FU revealed a synergistic effect (CI value $<1) .{ }^{*}$ Compared with PCa or 5-FU only vs. the combination group $(P<0.05)$.

prolonged survival time (from 27 to 35 days), indicating that PCa significantly inhibited the growth of CT26 tumors. In tissue TUNEL assays, there were obvious positive results in the PCa groups (Figure 6(c)). Moreover, there was no significant difference between the vehicle and PCa groups for body weight or organ histology, including the liver, kidney, and intestine (Figures 6(d) and 6(e). In short, these results suggested that PCa suppressed tumor growth via induction of cell apoptosis, with no significant side effects on the mice.

\section{Discussion}

Colorectal cancer is the most common type of gastrointestinal cancers and is a leading cause of cancer-related deaths among men and women worldwide [27]. Severe adverse effects and limitations in the therapeutic efficacy of conventional clinical drugs for cancer treatment have led to the widespread application of complementary and alternative medicine [28]. Among these treatments, traditional medicines with demonstrable bioactivity against cancer provide atleast 250 preferred choices [29]. In this study, we selected Pogostemon cablin to investigate its anti-CRC effect in vitro and in vivo. We used two CRC cells, namely, HT-29 (human colorectal adenocarcinoma) and CT26 cells (mouse colon carcinoma), to perform different experiments. HT-29 cells were used to examine the in vitro anticancer mechanism of PCa. The results demonstrated that PCa induced cell cycle arrest at $G_{0} / G_{1}$ phase via $p 53$ and p21 upregulation and CDKs/cyclins downregulation, then promoting cell apoptosis via activation of extrinsic and intrinsic cell apoptosis pathway. CT26 cells were used to evaluate the therapeutic effect on subcutaneous tumor in $\mathrm{BALB} / \mathrm{c}$ mice model. The results suggested that PCa suppressed CRC growth and induced cell apoptosis in vivo, where anticancer mechanisms were consistent with in vitro assays. These findings highlight the anticancer potential of $\mathrm{PCa}$ against colorectal carcinoma.
Cell proliferation is controlled by cell cycle progression, which is divided into four nonoverlapping phases, $G_{1}, S, G_{2}$, and $\mathrm{M}$, with a strong regulatory process, and it has checkpoints that cause cell cycle arrest [30]. Our study demonstrated that PCa induced cell cycle arrest at the $G_{0} / G_{1}$ phase in CRC cells, leading to a decrease in cell viability in time- and dose-dependent manners. p53 activation exerts tumor suppression through promoting the transcription of target genes such as p21 and p27 [31]. p21 belongs to the Cip/Kip family of CDK inhibitors that bind to cyclin/CDK complexes to inhibit activity, thereby subsequently arresting the cell cycle. CDK/ cyclins are divided into regulators of different cell cycle phases, including $\mathrm{G}_{0} / \mathrm{G}_{1}$ phase: cyclin $\mathrm{D}$ and $\mathrm{CDK}$ 4/6; $S$ phase: cyclin $\mathrm{E}$ and $\mathrm{CDK} 2$; and $\mathrm{G}_{2} / \mathrm{M}$ phase: cyclin $\mathrm{A}$, cyclin B1, and $\mathrm{CDK} 1 / 2$ [32]. In this study, treatment with $\mathrm{PCa}$ resulted in upregulation of p53 and p21 and downregulation of CDK2, CDK4, cyclin A, cyclin B1, and cyclin D1 proteins in timeand dose-dependent manners. Although the cell cycle assessment identified $\mathrm{G}_{0} / \mathrm{G}_{1}$ phase arrest, overall, the cell cyclerelated proteins decreased following exposure to PCa. In addition, downregulated expression of PCNA protein by $\mathrm{PCa}$ implied a decreased proliferation ability. These results suggest that PCa inhibits cell proliferation of CRC cells via cell cycle arrest, especially arrest at the $\mathrm{G}_{0} / \mathrm{G}_{1}$ phase, and upregulation of p53 and p21 proteins expression.

Apoptosis is a type of programmed cell death with specific morphological features, such as an increase of the cell population arrested in the sub- $G_{1}$ phase, chromatin condensation, DNA fragmentation, and apoptotic bodies, which is associated with activation of caspase cascades [33]. We found that PCa treatment significantly increased the accumulation of cells in the sub-G1 phase and induced cell apoptosis with typical apoptotic morphological features in vitro and in vivo by performing TUNEL assays. Apoptosis is induced via the regulation of caspase cascades, and caspases are divided into the initiators, including the extrinsic pathway (caspases-2, -8, and -10) and the intrinsic pathway 


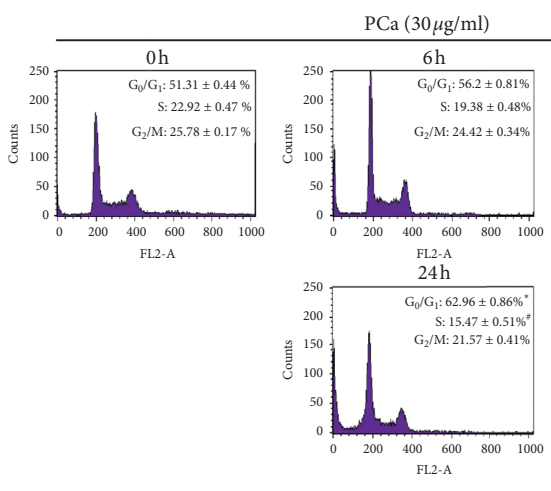

(a)
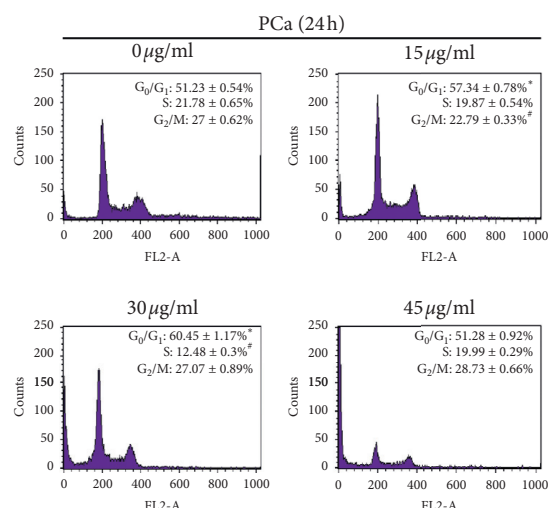

(b)
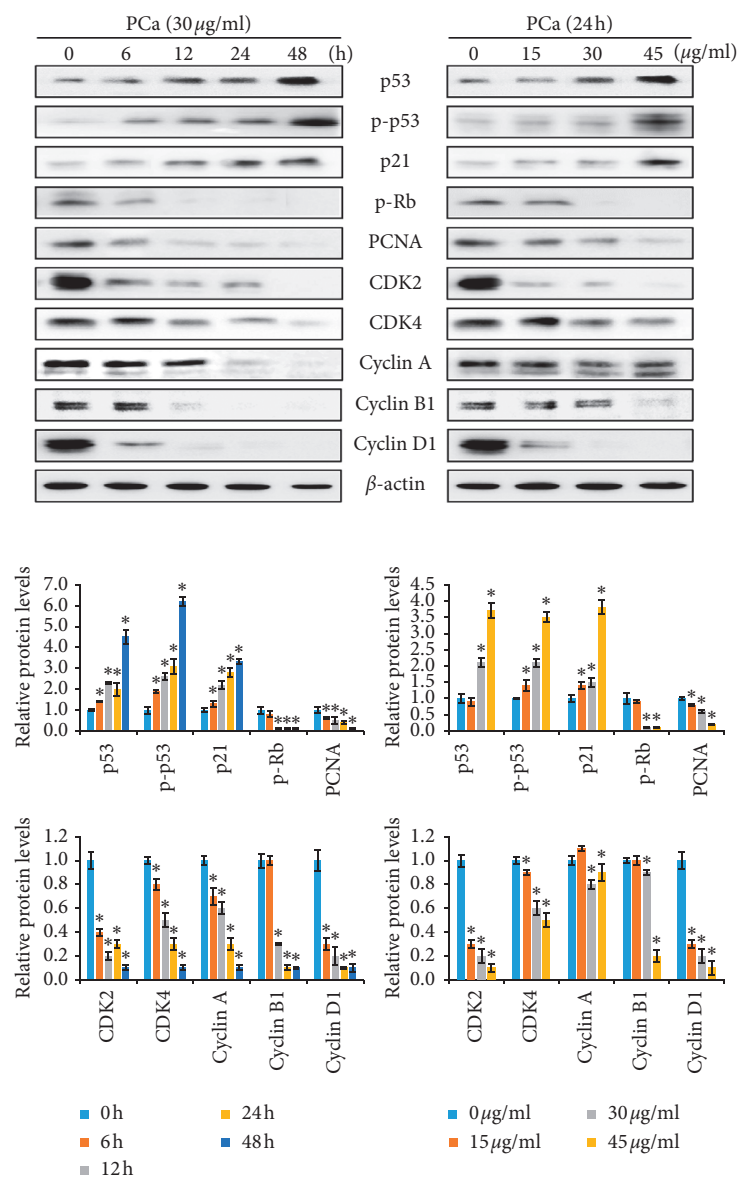

(c)

Figure 3: PCa induced $G_{0} / G_{1}$ phase cell cycle arrest by decreasing CDK4 and cyclin D1 expression. Cell cycle distribution $\left(G_{0} / G_{1}, S, G_{2} / M\right.$ phases) of HT-29 cells after treatment with $30 \mu \mathrm{g} / \mathrm{ml}$ PCa for $0-48 \mathrm{~h}$ (a); 15, 30, or $45 \mu \mathrm{g} / \mathrm{ml}$ PCa for $24 \mathrm{~h}$ (b) was detected and analyzed by flow cytometry and FlowJo software. The results are shown as mean $\pm \mathrm{SD} .{ }^{*} P<0.05$ versus control group with a significant increase. ${ }^{\#} P<0.05$ versus control group with a significant decrease. (c) Western blot showing the upregulation of the proteins p53 and p21, whereas downregulation of the proteins CDK4 and cyclin D1 was observed in HT-29 cells.

(caspase-9); and the effector (caspases-3, -6, and -7) caspases. Caspase- 3 is a key enzyme in the production of cysteinyl aspartate and is a central apoptosis regulator due to apoptosis being initiated by most triggers through the caspase-3-mediated pathway [33]. In this study, we showed that the levels of Fas, Bax, and caspases-3, -8, and -9 increased in CRC cells following PCa treatment. These results suggest that PCa induces cell apoptosis via induction of the extrinsic and intrinsic apoptosis pathways in CRC cells.

Previous studies demonstrated that Pogostemon species contained anticancer activity. An extract of Pogostemon benghalensis Linn. showed anticancer activity on Ehrlich ascites carcinoma in tumor-bearing mice [34]. Pogostemon cablin aqueous extract induced apoptosis in endometrial 


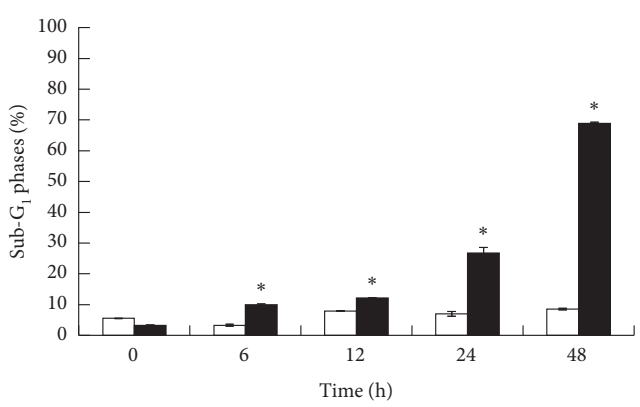

$\square$ Control

口Ca

(a)
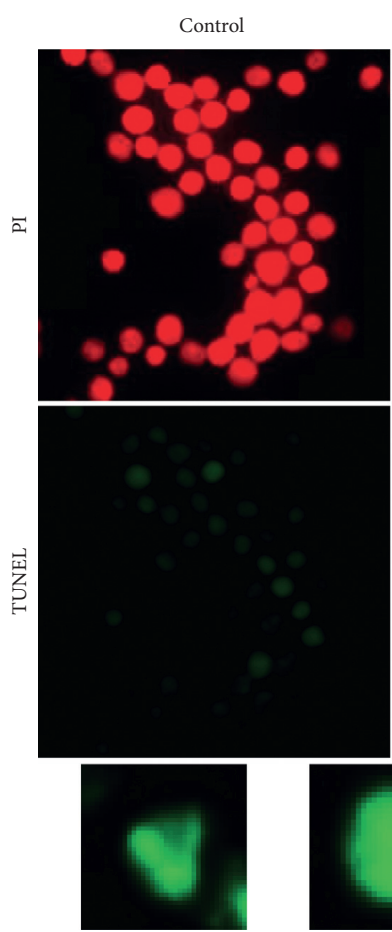

Chromatin condensation
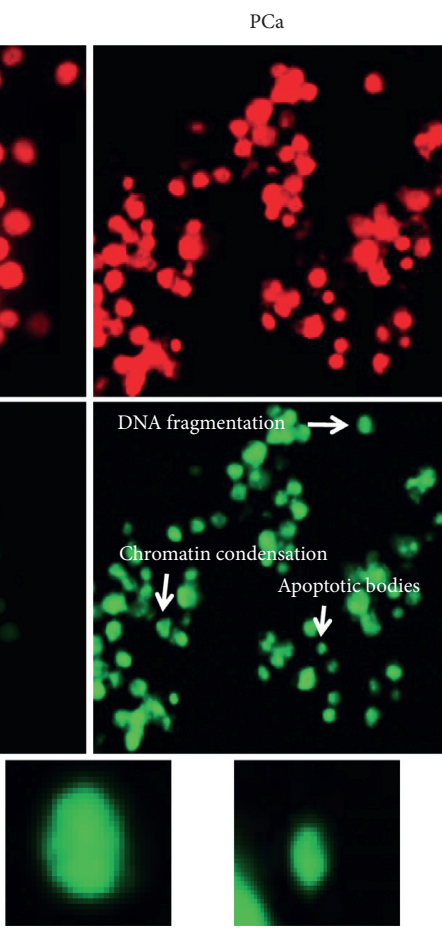

DNA fragmentation

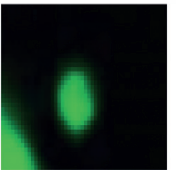

Apoptotic

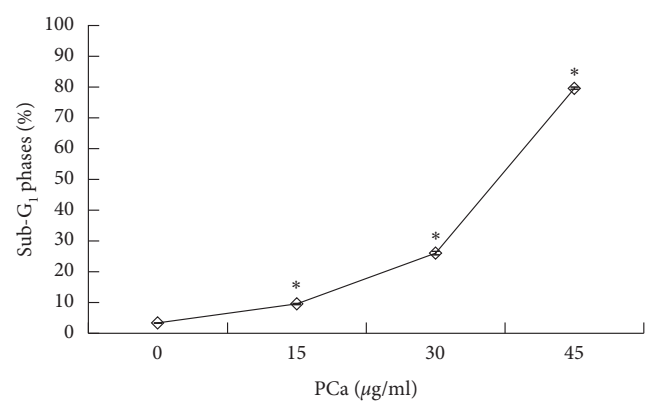

(b)
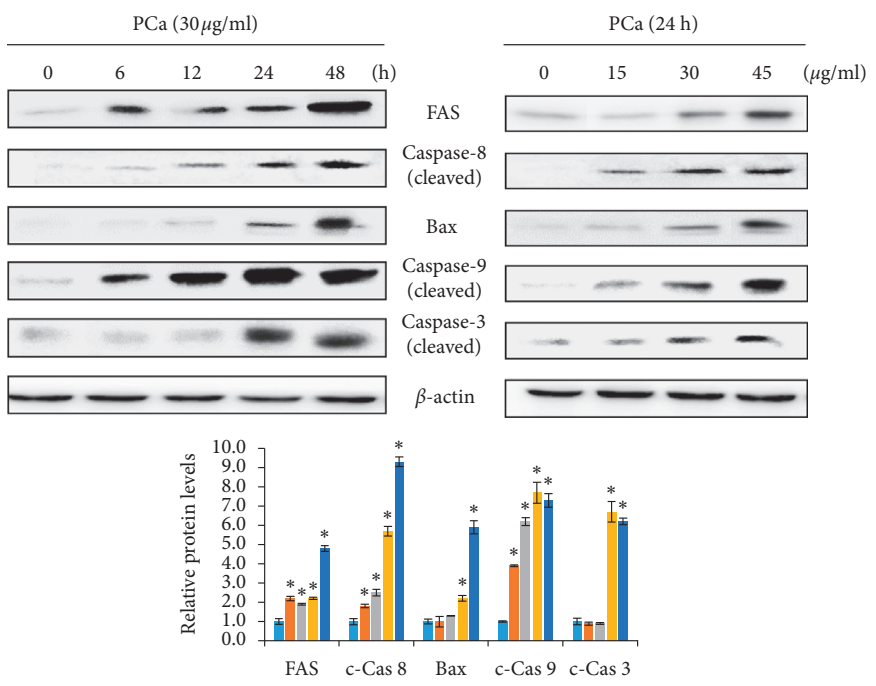

- $0 \mathrm{~h} \quad=24 \mathrm{~h}$

- $6 \mathrm{~h}-48 \mathrm{~h}$

- $12 \mathrm{~h}$

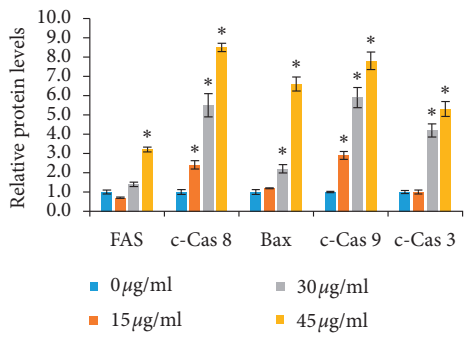

(d)

Figure 4: PCa triggered cell apoptosis through extrinsic and intrinsic pathways in HT-29 cells. (a, b) HT-29 cells were treated with PCa and analyzed for SubG 1 phase by flow cytometry. Data are expressed as mean $\pm \mathrm{SD} .{ }^{*} P<0.05$ versus control group with a significant increase. (c) The typical morphology of cell apoptosis, such as chromatin condensation, DNA fragmentation, and apoptosis body, was observed after PCa treatment for $48 \mathrm{~h}$ by using TUNEL assays. (d) Determination of the apoptosis pathway by Western blots of PCa-treated cells.

cancer (Ishikawa) cells [24]. Petroleum ether and chloroform leaf extracts of Pogostemon quadrifolius (Benth.) inhibited the growth of human colorectal (Caco-2), cervix (HeLa), monocytic leukemia (THP-1), breast (MCF-7), and leukemic T cell lymphoblast (Jurkat E6-1) cancer cells [35]. Pogostemon deccanensis essential oils have antiproliferation activity in the mouse cancer cell line B16F1 [36]. In this study, we demonstrated that PCa inhibited cell growth and induced cell apoptosis of CRC cells in vitro and in vivo.
Furthermore, the components in PCa were analyzed by GC-MS and identified by comparison with mass spectra from the literature and the NIST and Wiley Library databases. The major compounds smaller than 500 daltons in the PCa included azulene (21.81\%), $\alpha$-guaiene (18.85\%), patchouli alcohol (18.16\%), $\alpha$-patchoulene (11.14\%), $\gamma$-gurjunene $(9.31 \%)$, and others. Recent studies showed that azulene had antiproliferation activity against MCF7 breast cancer cells and DU145 prostate cancer cells, and different 

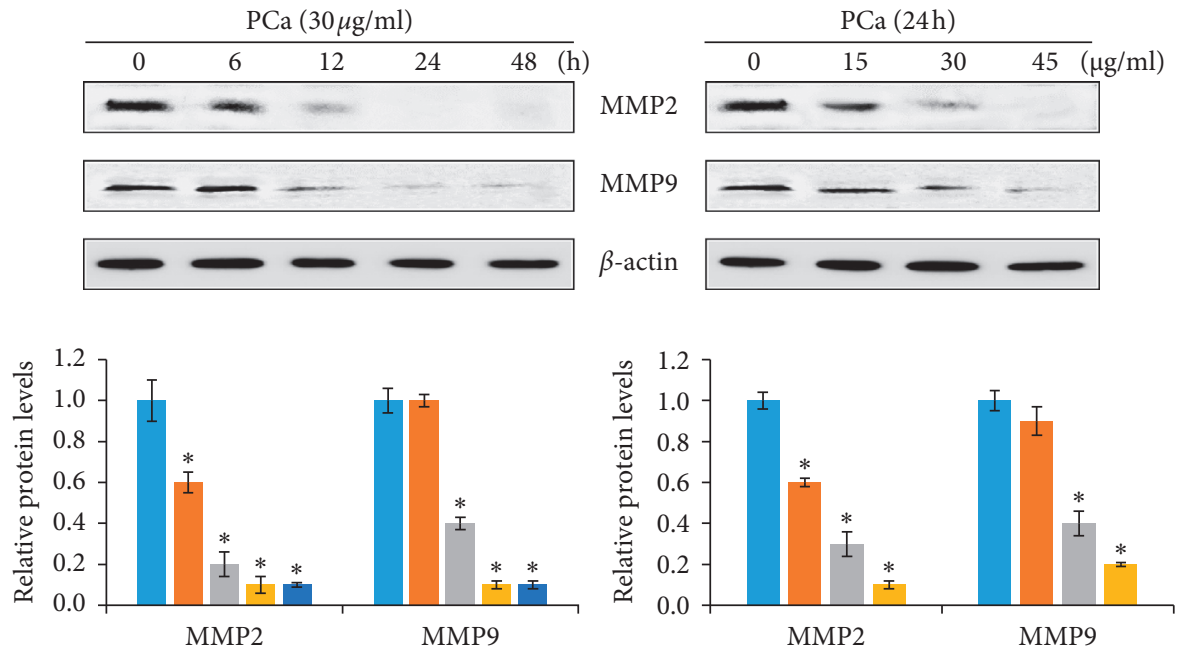
$0 \mathrm{~h}$
- $24 \mathrm{~h}$
- $0 \mu \mathrm{g} / \mathrm{ml}$
- $30 \mu \mathrm{g} / \mathrm{ml}$
$6 \mathrm{~h}$
- $48 \mathrm{~h}$
$15 \mu \mathrm{g} / \mathrm{ml}$
- $45 \mu \mathrm{g} / \mathrm{ml}$

Figure 5: The molecules involved in metastasis were affected by PCa treatment of HT-29 cells. Cells were treated with $30 \mu \mathrm{g} / \mathrm{ml} \mathrm{PCa} \mathrm{for} 0,6$, 12,24 , or $48 \mathrm{~h} ; 15,30$, or $45 \mu \mathrm{g} / \mathrm{ml}$ PCa for $24 \mathrm{~h}$, and the protein expression of MMP2 and MMP9 was analyzed by Western blotting. Protein bands were normalized using the corresponding $\beta$-actin to calculate the band density. MMP: matrix metallopeptidase.

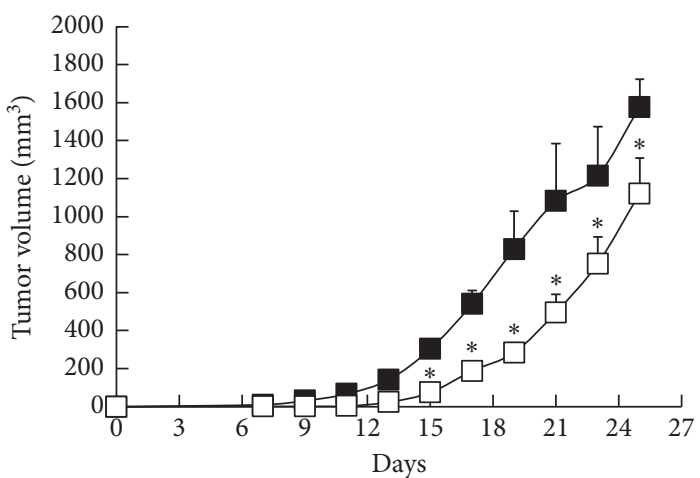

Vehicle $\square \mathrm{PCa}(200 \mathrm{mg} / \mathrm{kg})$

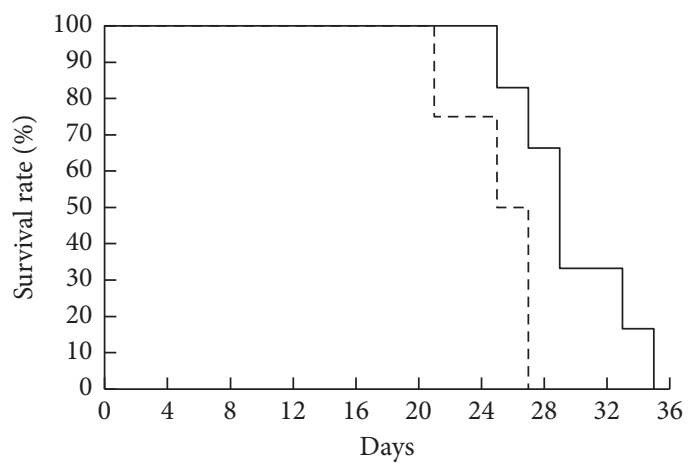

- - - Vehicle

— PCa $(200 \mathrm{mg} / \mathrm{kg})$

(a)

(b)

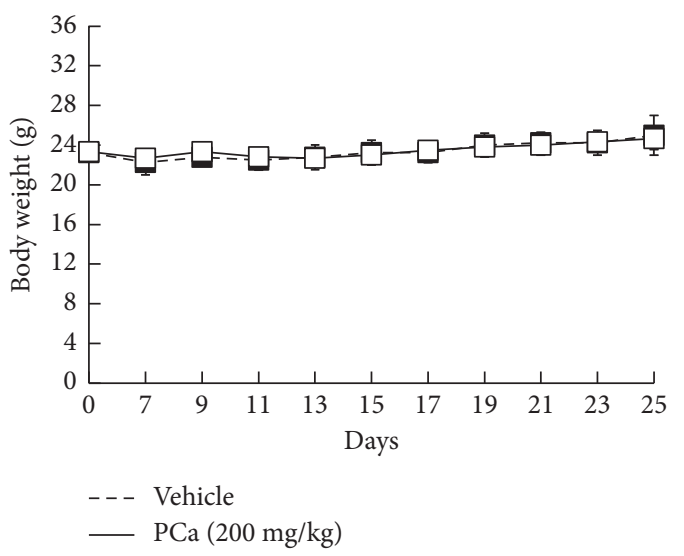

(c)

Figure 6: Continued. 


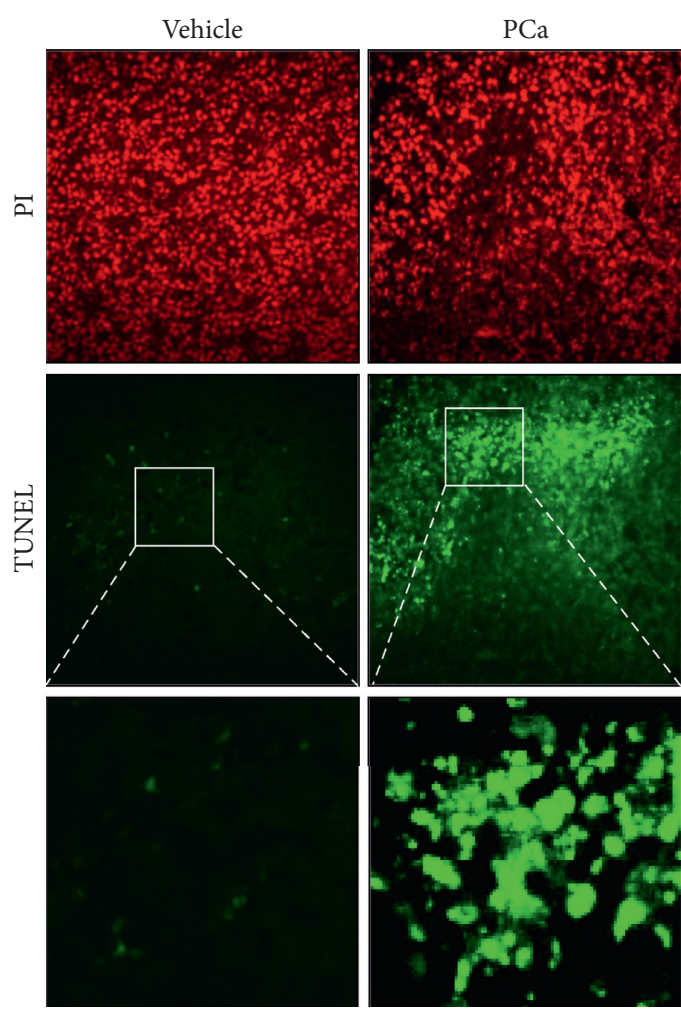

(d)

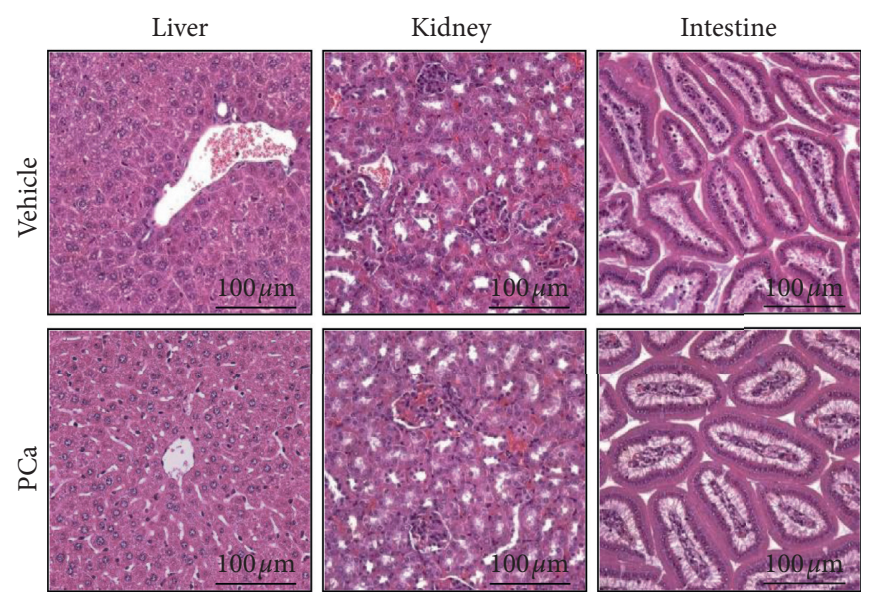

(e)

FIgURE 6: PCa suppressed tumor growth via induction of cell apoptosis in vivo. Mice were subcutaneously implanted with CT26 cells and treated (s.c.) with $200 \mathrm{mg} / \mathrm{kg}$ PCa once every two days for 40 days. Tumor volume (a), survival (b), and body weight (c) were recorded once every two days, and mice were sacrificed when the volume of the tumor exceeded $1500 \mathrm{~mm}^{3}$. Results are expressed as mean \pm SD. ${ }^{*} P<0.05$ versus the vehicle group. (d) Cell apoptosis was determined through tissue TUNEL assays. (e) HE staining of the organs, including liver, kidney, and intestine, was used for assessing toxicity.

substituted azulene derivatives have been developed [37]. Another component, $\alpha$-guaiene, was found to be responsible for most of the cytotoxic activity of Bulnesia sarmientoi against A549 and H661 lung cancer cells [38]. Exposure of HCT116 and SW480 colorectal cancer cells to patchouli alcohol activated p21 expression and inhibited the expression of cyclin D1 and CDK4 and induced cell apoptosis and cell cycle arrest in A549 lung cancer cells in vitro and in vivo via the EGFR-MAPK pathway $[39,40]$. A hexane fraction of guava leaves (Psidium guajava L.), which contained 3.76\% $\alpha$-patchoulene, inhibited the AKT/mTOR/S6K1 signaling pathway and induced apoptosis in prostate cancer cells [41]. The oleoresin extract of Dipterocarpus alatus (contained $3.14 \% \gamma$-gurjunene) showed cytotoxicity against human leukemic U937 cells [42]. These studies indicated that PCa contains various compounds with anticancer activity, suggesting that $\mathrm{PCa}$ has a high potential for development into an anticancer agent or adjuvant treatment in colorectal cancer therapy in the future.

\section{Conclusions}

PCa suppressed the cell growth of CRC in vitro and in vivo and, combined with the clinical drug 5-FU, synergistically inhibited proliferation of CRC cells. PCa induced cell cycle arrest at the $\mathrm{G}_{0} / \mathrm{G}_{1}$ phase and upregulated the expression of p53 and p21 and downregulated CDK4 and cyclin D1 proteins. PCa induces cell apoptosis via induction of the extrinsic (Fas/caspase-8) and intrinsic (Bax/caspase-9) apoptosis pathway in CRC cells. Moreover, PCa downregulated metastasis-associated proteins (MMP2/MMP9) expression. Thus, these results indicate that PCa should be investigated further for its potential contributions to CRC treatment.

\section{Data Availability}

All data generated or analyzed during this study are included in this published article.

\section{Conflicts of Interest}

The authors declare no conflicts of interest regarding the publication of this paper.

\section{Authors' Contributions}

J.-H.C. and N.-M.T. conceived, designed, and performed the experiments, analyzed data, and wrote the paper. S.-C.L. performed experiments and prepared the manuscript design. K.-F.C., X.-F.H., and Y.-T.C. performed experiments. 
All authors contributed to writing and editing and approved the manuscript for submission.

\section{Acknowledgments}

This work was supported by grants from Taichung Tzu Chi Hospital, Buddhist Tzu Chi Medical Foundation, Taiwan (Grants nos. TCCRD-106-20 and TTCRD-108-26). Flow cytometry (FACScan) was performed in the Instrument Center of Chung Shan Medical University, which is supported by the National Science Council, the Ministry of Education, and Chung Shan Medical University.

\section{References}

[1] M. P. Coleman, M. Quaresma, F. Berrino et al., "Cancer survival in five continents: a worldwide population-based study (CONCORD)," The Lancet Oncology, vol. 9, no. 8, pp. 730-756, 2008.

[2] J. Ferlay, M. Colombet, I. Soerjomataram et al., "Estimating the global cancer incidence and mortality in 2018: GLOBOCAN sources and methods," International Journal of Cancer, vol. 144, no. 8, pp. 1941-1953, 2019.

[3] R. Labianca, G. D. Beretta, B. Kildani et al., "Colon cancer," Critical Reviews in Oncology/Hematology, vol. 74, no. 2, pp. 106-133, 2010.

[4] S. De Dosso, C. Sessa, and P. Saletti, "Adjuvant therapy for colon cancer: present and perspectives," Cancer Treatment Reviews, vol. 35, no. 2, pp. 160-166, 2009.

[5] S. Kopetz, D. Freitas, A. F. Calabrich, and P. M. Hoff, "Adjuvant chemotherapy for stage II colon cancer," Oncology (Williston Park), vol. 22, no. 3, pp. 260-270, 2008.

[6] S. E. Campbell, W. L. Stone, S. Lee et al., "Comparative effects of RRR-alpha- and RRR-gamma-tocopherol on proliferation and apoptosis in human colon cancer cell lines," BMC Cancer, vol. 6, no. 13, 2006.

[7] J. G. Bieri and R. P. Evarts, "Gamma tocopherol: metabolism, biological activity and significance in human vitamin $\mathrm{E}$ nutrition," The American Journal of Clinical Nutrition, vol. 27, no. 9, pp. 980-986, 1974.

[8] D. McWhirter, N. Kitteringham, R. P. Jones, H. Malik, K. Park, and D. Palmer, "Chemotherapy induced hepatotoxicity in metastatic colorectal cancer: a review of mechanisms and outcomes," Critical Reviews in Oncology/ Hematology, vol. 88, no. 2, pp. 404-415, 2013.

[9] C. A. Rabik and M. E. Dolan, "Molecular mechanisms of resistance and toxicity associated with platinating agents," Cancer Treatment Reviews, vol. 33, no. 1, pp. 9-23, 2007.

[10] D. J. Newman and G. M. Cragg, "Natural products as sources of new drugs over the last 25 years $\perp$," Journal of Natural Products, vol. 70, no. 3, pp. 461-477, 2007.

[11] H. Yuan, Q. Ma, L. Ye, and G. Piao, "The traditional medicine and modern medicine from natural products," Molecules, vol. 21, no. 5, 2016.

[12] D. J. Newman and G. M. Cragg, "Natural products as sources of new drugs from 1981 to 2014," Journal of Natural Products, vol. 79, no. 3, pp. 629-661, 2016.

[13] S. Bernardini, A. Tiezzi, V. Laghezza Masci, and E. Ovidi, "Natural products for human health: an historical overview of the drug discovery approaches," Natural Product Research, vol. 32, no. 16, pp. 1926-1950, 2018.
[14] L. Pan, H. Chai, and A. D. Kinghorn, "The continuing search for antitumor agents from higher plants," Phytochemistry Letters, vol. 3, no. 1, pp. 1-8, 2010.

[15] X. Lin, Z. Peng, and C. Su, "Potential anti-cancer activities and mechanisms of costunolide and dehydrocostuslactone," International Journal of Molecular Sciences, vol. 16, no. 5, pp. 10888-10906, 2015.

[16] F. M. Millimouno, J. Dong, L. Yang, J. Li, and X. Li, “Targeting apoptosis pathways in cancer and perspectives with natural compounds from mother nature," Cancer Prevention Research, vol. 7, no. 11, pp. 1081-1107, 2014.

[17] S. Zeinoddini, M. Nabiuni, and H. Jalali, "The synergistic cytotoxic effects of doxorubicin and Viola odorata extract on human breast cancer cell line T47-D," Journal of Cancer Research and Therapeutics, vol. 15, no. 5, pp. 1073-1079, 2019.

[18] Y. Fang, C. Yang, L. Zhang et al., "Spica prunellae extract enhances fluorouracil sensitivity of 5-fluorouracil-resistant human colon carcinoma HCT-8/5-FU cells via TOP2alpha and miR-494," BioMed Research International, vol. 2019, Article ID 5953619, 2019.

[19] Y. Gan, G. Ai, J. Wu et al., "Patchouli oil ameliorates 5fluorouracil-induced intestinal mucositis in rats via protecting intestinal barrier and regulating water transport," Journal of Ethnopharmacology, vol. 250, Article ID 112519, 2020.

[20] J. S. Chia, J. L. Du, W. B. Hsu, A. Sun, C. P. Chiang, and W. B. Wang, "Inhibition of metastasis, angiogenesis, and tumor growth by Chinese herbal cocktail Tien-Hsien liquid," BMC Cancer, vol. 10, p. 175, 2010.

[21] A. Sun, J.-S. Chia, C.-P. Chiang et al., "The Chinese herbal medicine Tien-Hsien liquid inhibits cell growth and induces apoptosis in a wide variety of human cancer cells," The Journal of Alternative and Complementary Medicine, vol. 11, no. 2, pp. 245-256, 2005.

[22] M. Chen, J. Zhang, Y. Lai et al., "Analysis of Pogostemon cablinfrom pharmaceutical research to market performances," Expert Opinion on Investigational Drugs, vol. 22, no. 2, pp. 245-257, 2013.

[23] M. Swamy and U. Sinniah, "A comprehensive review on the phytochemical constituents and pharmacological activities of Pogostemon cablin benth: an aromatic medicinal plant of industrial importance," Molecules, vol. 20, no. 5, pp. 8521-8547, 2015.

[24] C. C. Tsai, Y. H. Chang, C. C. Chang et al., "Induction of apoptosis in endometrial cancer (Ishikawa) cells by Pogostemon cablin aqueous extract (PCAE)," International Journal of Molecular Sciences, vol. 16, no. 6, pp. 12424-12435, 2015.

[25] T.-C. Chou, "Drug combination studies and their synergy quantification using the Chou-Talalay method," Cancer Research, vol. 70, no. 2, pp. 440-446, 2010.

[26] H.-W. Gao, K.-F. Chang, X.-F. Huang et al., "Antitumor effect of n-butylidenephthalide encapsulated on B16/F10 melanoma cells in vitro with a polycationic liposome containing PEI and polyethylene glycol complex," Molecules, vol. 23, no. 12, 2018.

[27] L.-L. Tong, P. Gao, Z.-N. Wang et al., "Is the seventh edition of the UICC/AJCC TNM staging system reasonable for patients with tumor deposits in colorectal cancer?" Annals of Surgery, vol. 255, no. 2, pp. 208-213, 2012.

[28] J. Y. Tan, A. Molassiotis, T. Wang, and L. K. Suen, "Current evidence on auricular therapy for chemotherapy-induced nausea and vomiting in cancer patients: a systematic review of randomized controlled trials," Evidence-Based Complementary and Alternative Medicine, vol. 2014, Article ID 430796, 18 pages, 2014. 
[29] J. M. Fouladbakhsh, L. Balneaves, and E. Jenuwine, "Understanding CAM natural health products: implications of use among cancer patients and survivors," Journal of the Advanced Practitioner in Oncology, vol. 4, no. 5, pp. 289-306, 2013.

[30] S. Maddika, S. R. Ande, S. Panigrahi et al., "Cell survival, cell death and cell cycle pathways are interconnected: implications for cancer therapy," Drug Resistance Updates, vol. 10, no. 1-2, pp. 13-29, 2007.

[31] S. L. Harris and A. J. Levine, "The p53 pathway: positive and negative feedback loops," Oncogene, vol. 24, no. 17, pp. 2899-2908, 2005.

[32] M. Peyressatre, C. Prével, M. Pellerano, and M. Morris, "Targeting cyclin-dependent kinases in human cancers: from small molecules to peptide inhibitors," Cancers, vol. 7, no. 1, pp. 179-237, 2015.

[33] S. Elmore, "Apoptosis: a review of programmed cell death," Toxicologic Pathology, vol. 35, no. 4, pp. 495-516, 2007.

[34] M. Patel, B. Antala, E. Dowerah, R. Senthilkumar, and M. Lahkar, "Antitumor activity of Pogostemon benghalensis Linn. on ehrlich ascites carcinoma tumor bearing mice," Journal of Cancer Research and Therapeutics, vol. 10, no. 4, pp. 1071-1075, 2014.

[35] S. Cheriyamundath, R. Raghavan, A. Banerji et al., "Bioassayguided isolation and evaluation of antiproliferative effects of (Z)-Ethylidene-4, 6-dimethoxycoumaran-3-one from Pogostemon quadrifolius (benth.)," Asian Pacific Journal of Cancer Prevention: APJCP, vol. 18, no. 7, pp. 1783-1790, 2017.

[36] V. Kumar, V. Shriram, R. Bhagat, T. Khare, S. Kapse, and N. Kadoo, "Phytochemical profile, anti-oxidant, anti-inflammatory, and anti-proliferative activities of Pogostemon deccanensis essential oils," 3 Biotech, vol. 9, no. 1, p. 31, 2019.

[37] F. Ayaz, A. Yuzer, T. Ince, and M. Ince, "Anti-cancer and antiinflammatory activities of bromo- and cyano-substituted azulene derivatives," Inflammation, vol. 43, no. 3, pp. 1009-1018, 2020.

[38] H. L. Wang, J. C. Chang, L. W. Fang et al., "Bulnesia sarmientoi supercritical fluid extract exhibits necroptotic effects and anti-metastatic activity on lung cancer cells," Molecules, vol. 23 , no. 12,2018 .

[39] J. B. Jeong, J. Choi, Z. Lou, X. Jiang, and S.-H. Lee, "Patchouli alcohol, an essential oil of Pogostemon cablin, exhibits antitumorigenic activity in human colorectal cancer cells," International Immunopharmacology, vol. 16, no. 2, pp. 184-190, 2013.

[40] X. Lu, L. Yang, C. Lu et al., "Molecular role of EGFR-MAPK pathway in patchouli alcohol-induced apoptosis and cell cycle arrest on A549 cells in vitro and in vivo," BioMed Research International, vol. 2016, Article ID 4567580, 12 pages, 2016.

[41] N. H. Ryu, K.-R. Park, S.-M. Kim et al., "A hexane fraction of guava Leaves (Psidium guajava L.) induces anticancer activity by suppressing AKT/mammalian target of rapamycin/ribosomal p70 S6 kinase in human prostate cancer cells," Journal of Medicinal Food, vol. 15, no. 3, pp. 231-241, 2012.

[42] C. Yongram, B. Sungthong, P. Puthongking, and N. Weerapreeyakul, "Chemical composition, antioxidant and cytotoxicity activities of leaves, bark, twigs and oleo-resin of Dipterocarpus alatus," Molecules, vol. 24, no. 17, 2019. 